\title{
Quality of Experience Assessment of Video Quality in Social Clouds
}

\author{
Asif Ali Laghari, ${ }^{1}$ Hui He, ${ }^{1}$ Shahid Karim, ${ }^{2}$ Himat Ali Shah, ${ }^{3}$ and Nabin Kumar Karn ${ }^{1}$ \\ ${ }^{1}$ School of Computer Science \& Technology, Harbin Institute of Technology, Harbin, China \\ ${ }^{2}$ School of Electronics and Information Engineering, Harbin Institute of Technology, Harbin, China \\ ${ }^{3}$ Department of Information Technology, QUEST, Nawabshah, Pakistan \\ Correspondence should be addressed to Hui He; hehui@hit.edu.cn
}

Received 5 September 2017; Revised 7 November 2017; Accepted 28 November 2017; Published 26 December 2017

Academic Editor: Shingo Yamaguchi

Copyright (C) 2017 Asif Ali Laghari et al. This is an open access article distributed under the Creative Commons Attribution License, which permits unrestricted use, distribution, and reproduction in any medium, provided the original work is properly cited.

Video sharing on social clouds is popular among the users around the world. High-Definition (HD) videos have big file size so the storing in cloud storage and streaming of videos with high quality from cloud to the client are a big problem for service providers. Social clouds compress the videos to save storage and stream over slow networks to provide quality of service (QoS). Compression of video decreases the quality compared to original video and parameters are changed during the online play as well as after download. Degradation of video quality due to compression decreases the quality of experience (QoE) level of end users. To assess the QoE of video compression, we conducted subjective (QoE) experiments by uploading, sharing, and playing videos from social clouds. Three popular social clouds, Facebook, Tumblr, and Twitter, were selected to upload and play videos online for users. The QoE was recorded by using questionnaire given to users to provide their experience about the video quality they perceive. Results show that Facebook and Twitter compressed HD videos more as compared to other clouds. However, Facebook gives a better quality of compressed videos compared to Twitter. Therefore, users assigned low ratings for Twitter for online video quality compared to Tumblr that provided high-quality online play of videos with less compression.

\section{Introduction}

Nowadays, video posting and sharing are growing over the social clouds and users share their memories and events of life with friends around the world. Smartphones are now commonly used to record video with HD quality and have Internet access for sharing on the social clouds such as Facebook, Twitter, Tumblr, and Google Plus [1]. Users upload and share HD videos on social clouds but social clouds compress video files for fast loading of the web page, save storage because of a large amount of video data, and provide QoS delivery of video streaming over low-bandwidth networks [2-4]. The purpose of video compression is efficiently reducing visual data by avoiding the loss of visual quality due to compression [5]. To achieve video compression rate with minimum loss of visual data, several algorithms and video coding standards such as MPEG-1, MPEG-2, MPEG4, H.263, and H.264/AVC are developed [5, 6].
Social clouds store and compress video data by using different video coding standards, so their compression ratios are different from each other and impact on video quality is also different. Page loading with HD-quality video is also a major problem because page requires more network bandwidth to transfer data from cloud to user and computing resources for video processing [7]. The video posted on the social cloud contains distortion and noise as compared to the original one. Compressed videos are available online for perceiving and downloading in low quality on the social clouds which decreases the QoE of the user about the social clouds, but these videos will not be recovered in original format in which the video was recorded. Social clouds provide new features of videos hosting and play to attract users to increase the popularity of their organization and generate more revenue [8]. So every social cloud provides customer feedback service to collect user experience about their services but mostly users do not interact with the social service provider and migrate to another social cloud for better QoS. 
Social clouds focus on the quality of service by improving hardware infrastructure instead of QoE parameters, which will not express the demand of end user. Quality of experience is defined as "a blueprint of all human subjective and objective quality needs and experiences arising from the interaction of a person with technology and with business entities in a particular context" [9]. Subjective QoE methods are used for the assessment of user feedback about video quality, video streaming, and network services [10]. QoE can be captured by using two methods: one is subjective and the other is objective. Objective QoE is subdivided into two methods: (i) technical QoS data and (ii) cognitive systems and Human physiological tests $[11,12]$. Providing the QoS for video hosting is a challenge for social cloud service providers because $\mathrm{HD}$ videos take more time to load into a webpage and the high data size of the video also consumes more storage amount at cloud side and requires more network bandwidth to transfer from cloud to client. The main contribution of this paper is to study and explore the influence of different social clouds' video hosting and compression over the user QoE.

We used subjective QoE method to access user satisfication level for different social cloud service providers and solution also provides the acceptable level of online streaming of compressed videos as compared to the original video. During the research work, we repeat experiments with four videos that have different quality, 2K (1440 P), $720 \mathrm{P} \mathrm{HD}$, $360 \mathrm{P}$, and $240 \mathrm{P}$, which were taken from YouTube and posted on Facebook, Tumblr, and Twitter for the user to perceive online video to assign ratings and examine the characteristics and effect on the QoE of video quality.

Our paper is organized into 5 sections: in Section 2 we provide the literature review and Section 3 is based on lab experiments. Section 4 provides results and discussion; finally, in Section 5, we conclude our work.

\section{Literature Review}

QoE assessment of video streaming was investigated in clientserver architecture and impact of network parameters on the video quality and codecs were considered. Video hosting and streaming on social clouds were never investigated by anyone in research work by using video compression parameter. We include literature of analysis of different factors on video streaming such as the distance between cloud and user and subjective QoE of live video streaming over social clouds.

Impact of distance between the clouds and end users on the QoE was investigated by Laghari et al. [13]. During the QoE assessment experiments, three different-quality videos having different bitrate, resolution, and codecs were posted on the four clouds' nearby location and long distance. Network delay response of each cloud was captured by using the ping command. Users perceived video from each cloud and provided their QoE assessment by using questionnaire and the result shows that user assigns high ratings for nearby location clouds for video streaming and low ratings for long distance clouds. Long distance causes delay of network traffic, which affects the QoE of users when they access videos from clouds.
Many researchers have done work on the live video streaming in cloud computing such as Cheng [14] who proposed framework for adoption of user requirement with minimum utilization of cloud resources without affecting the quality of video streaming. The cloud-based media processing framework processes large number of video streams of the live broadcast in clouds. Wang et al. [15] presented a solution by using software-defined networks that support alternative path for continuous, scalable live video streaming service in a cloud environment to fill user requirement.

In summary, researchers have done work on the cloudbased video streaming and analyzed the QoE of end users by using different parameters but no such work provided the assessment of user's QoE for video compression in social clouds. To overcome this problem of video compression in social clouds, we conducted subjective QoE of end users by posting and streaming video from social clouds.

\section{QoE Assessment Design and Experiment}

In order to collect QoE of the users for video streaming and quality on social clouds, we performed various experiments and asked users to watch and perceive the videos on the social clouds and ranked the videos for smooth play and quality of the video. Four videos with different resolution and quality, 2K (1440 P), $720 \mathrm{p}, 360 \mathrm{P}$, and $260 \mathrm{P}$, were selected from YouTube. Videos were downloaded from YouTube and uploaded (posted) on the leading social cloud storages Facebook, Tumblr, and Twitter. During the posting of videos, every cloud reduces the quality of video (data rate, total bitrate, and size and changes the audio bitrate) which varies according to cloud's own secret compression preferences.

QoE assessment experiment was conducted with 134 users; among them, 81 were female and 53 were male subjects, aged between 20 and 30 years. The majority of students belonged to Computer Science and Technology Department and the rest of other departments; few of them were postgraduate students and others were undergraduate students. A questionnaire was given to users and they were asked to provide their profile and assign rating for video quality which they perceive during the online play of video from the social clouds.

For video display purpose, we follow the recommendations of ITU-R [16] and ITU-T Rec. [17]. The display setting for watching videos was 21-inch LCD display, which has a resolution of $1280 \times 800$. Videos were played in sequence. For subjects, first original videos which were downloaded from YouTube were played and then cloud-hosted videos were played online in real-time streaming from every social cloud but subjects were unaware of the technical details of videos like data rate, total bitrate, size, and changes of the audio bitrate. Before playing the online video, during the experiment, and after completion of watching online streaming of videos, network speed was measured by using the following popular site: http://www.speedtest.net. The download speed of the network is $5.76 \mathrm{MB}$ and upload recorded $3.78 \mathrm{MB}$ during the experiment. 
3.1. Selection of Videos. The video clips named "Samsung UHD Demo" ( $2 \mathrm{~K}=1440$ P), "Fearless-Daffy-Duck" (720 P), and "Motivate yourself" (360 P) and Short wildlife video $(240 \mathrm{P})$ were used for experiments during QoE assessment of users for social clouds, which were downloaded from YouTube [18-21], and snapshots are given in Figures 1-4 with quality parameters. The purpose of selecting $2 \mathrm{~K}(1440 \mathrm{P})$ to lowest-resolution, $240 \mathrm{P}$, video is to conduct QoE assessment experiment of the user on high quality and low quality to find which is the best acceptable video quality for hosting on the social clouds. "Samsung UHD Demo" $(2 \mathrm{~K}=1440 \mathrm{P})$ and Fearless-Daffy-Duck $720 \mathrm{P}$ HD videos are selected for QoE assessment experiment because users always want to share HD multimedia video on the social clouds and lowquality videos, $360 \mathrm{P}$ and $240 \mathrm{P}$, were also used in experiments for social cloud's compression analysis and user ratings. So the HD and low-quality videos are selected to find QoE assessment of users and also degradation of the quality of video after uploading on the social clouds. The technical details of videos such as format, frame rate, frame resolution (width and height), audio bitrate, data rate, total bitrate, and size are given in Table 1.

\section{Results and Discussion}

VLC player (version 2.2.1 Terry Pratchett (weatherwax)) [22] is used for opening and playing videos which were downloaded from social clouds. We conducted QoE test of video quality degradation due to compression hosted on social clouds in real-time environment. The purpose of using four different videos having different sizes, resolutions, and formats (media codecs) is to get more data about the user experience of different parameters which provide more detailed information of user perception and satisfaction.

All videos' parameters were analyzed and report logs were generated by using MediaInfo software tool (version 0.7.97) developed by MediaArea.net SARL [23]. The MediaInfo tool decodes all information of videos which were compressed during the upload to Facebook, Tumblr, and Twitter. Table 2 provides information of compression status of "Samsung UHD Demo" ( $2 \mathrm{~K}=1440 \mathrm{P})$ video of each cloud compared to original video file. The videos have difference in data rate, total bitrate, audio bitrate, and storage size.

Impact of lossy compression is different on user's QoE as compared to the original video. Facebook, Tumblr, and Twitter compressed videos by decreasing data rate and total bitrate but Tumblr and Twitter did not compress the audio bitrate to reduce the storage size on the cloud. For example, Facebook compressed to $86 \%$ data rate, $84.8 \%$ total bitrate, and $62 \%$ audio bitrate to reduce file size to be as low as $3.14 \mathrm{MB}$; the original one was $20.5 \mathrm{MB}$. Tumblr slightly less compressed $75.65 \%$ of total bitrate compared with Facebook and $77.42 \%$ of data rate but did not compress the audio bitrate. It reduces storage file size down to $4.99 \mathrm{MB}$ as the original one was $20.5 \mathrm{MB}$ but does not have a high impact on the diminishing of video quality. The same way Twitter compressed $79.66 \%$ data rate and $77.77 \%$ total bitrate and increased $2 \%$ audio bitrate to reduce the file size to be as low as
4.53 MB. Twitter provided good quality for downloaded video as given in detail in Table 2 but playing the video online has low quality as shown in Figure 7 where text in image marked in the red rectangle is distorted as compared to Figures 5 and 6 . Effects of video quality degradation during posting and during the online streaming from the social clouds are shown in Figures 5-7 and technical parameters comparison of the original video with posted videos on the social clouds is given in Table 2.

"Fearless-Daffy-Duck" (720 P) video was uploaded on the social clouds and parameters of the video were changed by applying compression by all social clouds. Facebook and Twitter compressed videos by decreasing data rate, total bitrate, and audio bitrate but Tumblr was the only social cloud which compressed the audio bitrate to reduce the storage size on the cloud; the rest of the parameters were the same as the original file. For example, Facebook compressed to $42 \%$ data rate, $46 \%$ total bitrate, and $75 \%$ audio bitrate to reduce file size to be as low as $5.9 \mathrm{MB}$; the original one was $10.9 \mathrm{MB}$. Tumblr slightly compressed $1 \%$ of total bitrate and $44 \%$ of audio bitrate to reduce storage file size but does not have a high impact on the video quality. The same way Twitter compressed $9 \%$ data rate, $12 \%$ total bitrate and $44 \%$ audio bitrate to reduce file size 9.6 MB. Twitter provided HD quality of downloaded videos as given in detail in Table 3 but playing the video online has low quality as shown in Figure 10 where text in image marked in the red rectangle is distorted as compared to Figures 8 and 9. Effects of video quality degradation during posting and during the online streaming from the social clouds are shown in Figures 8-10 and technical parameters comparison of the original video with posted videos on the social clouds is given in Table 3.

Low-quality, 360 p, video "Motivate yourself" was posted on social clouds and Facebook compressed 15\% data rate, $30 \%$ total bitrate, and $80 \%$ audio bitrate to reduce file size to be as low as $1.65 \mathrm{MB}$; the original one was $2.33 \mathrm{MB}$. Tumblr increased $1 \%$ of total bitrate and the storage file size is increased compared to original file but does not have high impact on the diminishing of video quality. The same way Twitter compressed $47 \%$ data rate, $42 \%$ total bitrate, and $29 \%$ audio bitrate to reduce file size to be 1.29 MB. Effects of video quality degradation during posting and during the online streaming from the social clouds are shown in Figures 11-13 and technical parameters comparison of the original video with posted videos on the social clouds is given in Table 4.

Short wildlife video $(240 \mathrm{P})$ was posted on social clouds to explore the compression parameters for lowest quality video and user ratings. Facebook compressed 37.6\% data rate, 53\% total bitrate, and $84.3 \%$ audio bitrate to reduce file size to be as low as $717 \mathrm{~Kb}$; the original one was $1.45 \mathrm{MB}$. Tumblr did not reduce the data rate and audio bitrate of the video but increased $1 \%$ of total bitrate and the storage file size is increased up to $1.46 \mathrm{MB}$ compared to original file, $1.45 \mathrm{MB}$, but does not have high impact on the video quality. The same way Twitter compressed $42 \%$ data rate, $53 \%$ total bitrate, and $75 \%$ audio bitrate to reduce file size to $700 \mathrm{~KB}$. Effects of video quality degradation during posting and during the online streaming from the social clouds are shown in Figures 14-16 


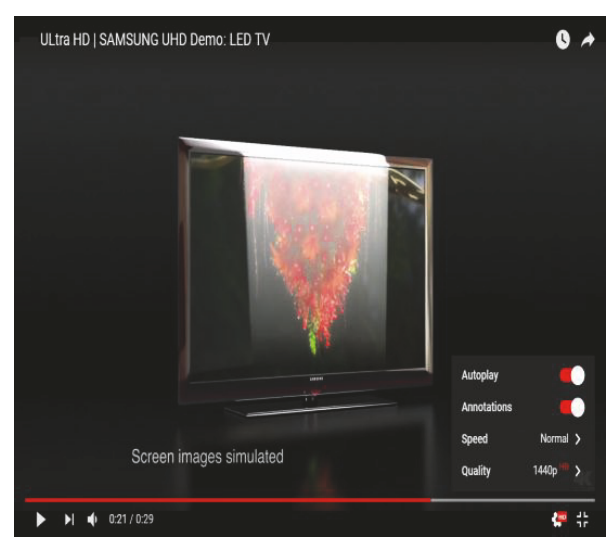

FIgURE 1: Snapshot of original video (Samsung Demo).

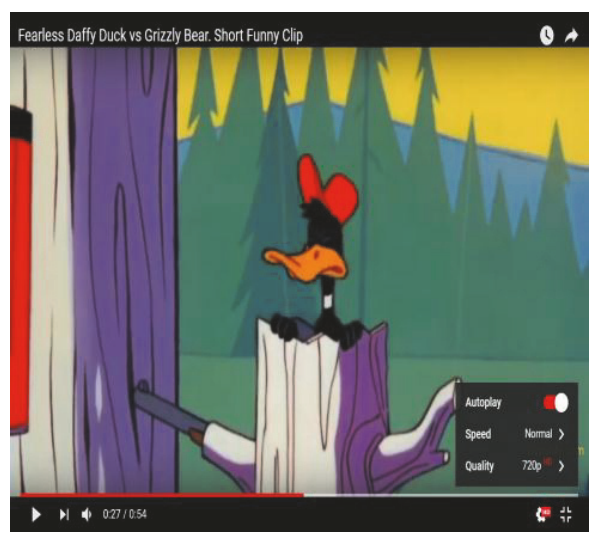

FIGURE 2: Snapshot of original video (Daffy).

and technical parameters comparison of the original video with posted videos on the social clouds is given in Table 5 .

4.1. Mean Opinion Score. We conducted the experiments and presented results of video compression parameters of four videos, which were posted on social clouds and downloaded for user video quality perception on each video in the experiments. If the users perceive that the quality of the video is better, then they assign rating as excellent, and if they are merely satisfied then they ranked video as fair. If they are completely dissatisfied, the quality of the video is annoying and is ranked as bad. Network parameters were not considered during playing online video from social clouds because network speed was enough to play videos without buffering/delay situation. During the experiment, the situation of buffering/delay due to low network speed or peak network traffic was never experienced. Results of experiments are given in Table 6.

The result shows that videos posted on social clouds have different QoE ratings of the same original videos. Facebook and Tumblr have high QoE ratings because both compress less video-related parameters like data rate and total bitrate but compress audio bitrate more to reduce file size when uploaded on the user's timeline, so quality is better compared to Twitter. Samsung UHD Demo 1440 P HD video was

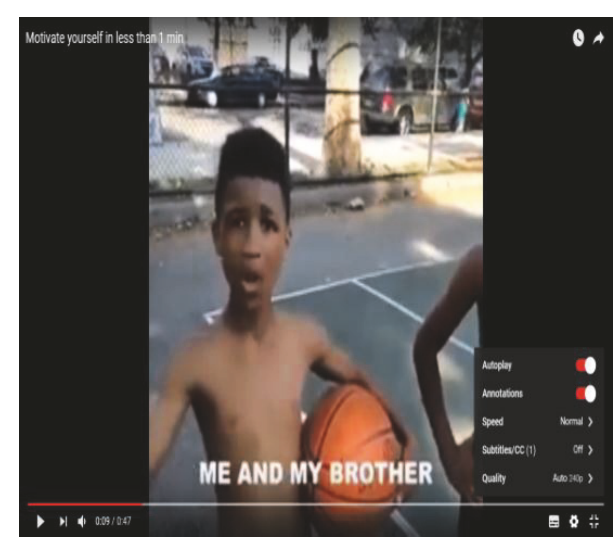

FIGURE 3: Snapshot of original video (Motivation).

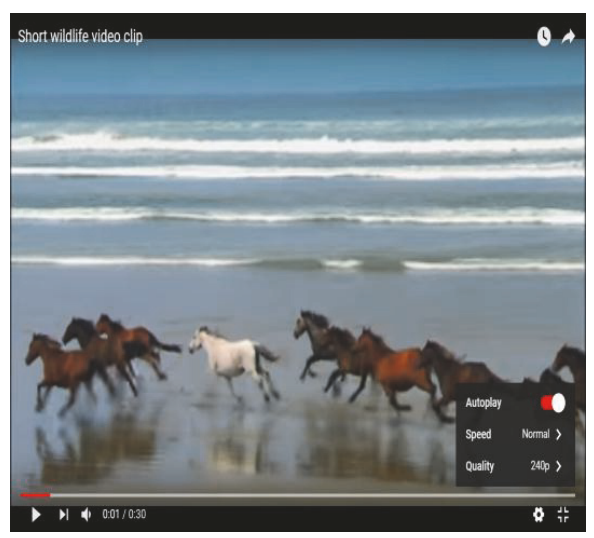

Figure 4: Snapshot of original video (Wildlife).

played online for users to watch and assign ratings. The user assigns high ratings to original video because of high quality with high data rate and bitrate but when the video was uploaded on social clouds then it was compressed by social clouds automatically and video quality is damaged due to compression of data rate and bitrate. The user assigned low ratings for Twitter video because it is highly compressed as compared to others such as Facebook and Tumblr videos which are shown in Figure 17.

Figure 18 shows high ratings for original $720 \mathrm{P}$ video of Facebook and Tumblr but low ratings for Twitter due to high compression of video. The technical information of video 720 is shown in Table 3. Facebook compressed $46 \%$ of original video file size as compared to Tumblr and Twitter, but quality of online played video is better than Twitter, where Twitter compressed less video file compared to Facebook but online playing quality is poor [24]. The users assigned low ratings which were considered as poor and bad category according to ITU recommendations [16].

$360 \mathrm{P}$ video has low QoE ratings for the original video because $360 \mathrm{P}$ is low-quality video as compared to $1440 \mathrm{P}$ and 720 P. Facebook compressed $30 \%$ and Twitter $45 \%$ of the file by decreasing data rate, total bitrate, and audio bitrate but Tumblr increased the file size by increasing total bitrate 
TABLE 1: Original videos' parameters.

\begin{tabular}{|c|c|c|c|c|}
\hline Technical parameters & $\begin{array}{c}\text { Samsung UHD Demo } \\
\quad(2 \mathrm{~K}=1440 \mathrm{P}) \\
\end{array}$ & $\begin{array}{l}\text { Fearless-Daffy-Duck } \\
\text { (720 P HD) }\end{array}$ & Motivate yourself (360 P) & $\begin{array}{l}\text { Short wildlife } \\
\text { video }(240 \mathrm{P})\end{array}$ \\
\hline Frame width & 2560 & 1280 & 360 & 320 \\
\hline Frame height & 1440 & 720 & 360 & 180 \\
\hline Data rate & $5667 \mathrm{kbps}$ & $1493 \mathrm{kbps}$ & $311 \mathrm{kbps}$ & $269 \mathrm{kbps}$ \\
\hline Total bitrate & $5774 \mathrm{kbps}$ & $1687 \mathrm{kbps}$ & $409 \mathrm{kbps}$ & $405 \mathrm{kbps}$ \\
\hline Frame rate & 30 frames/sec & 25 frames/sec & 29.9 frames/sec & 29.9 frames/sec \\
\hline Audio bitrate & $126 \mathrm{kbps}$ & $192 \mathrm{kbps}$ & $96 \mathrm{kbps}$ & $128 \mathrm{kbps}$ \\
\hline Storage size & $20.5 \mathrm{MB}$ & $10.9 \mathrm{MB}$ & $2.33 \mathrm{MB}$ & $1.45 \mathrm{MB}$ \\
\hline Playing length & $29 \mathrm{sec}$ & $54 \mathrm{sec}$ & $47 \mathrm{sec}$ & $30 \mathrm{sec}$ \\
\hline Format (media type) & MP4 (base media) & $\begin{array}{c}\text { MP4 (Moving Picture } \\
\text { Experts Group version 4) }\end{array}$ & $\begin{array}{l}\text { MP4 (base media/version } \\
\text { 2) }\end{array}$ & MP4 (base media) \\
\hline
\end{tabular}

TABLE 2: Original versus cloud compressed videos' parameters (Samsung UHD Demo $(2 \mathrm{~K}=1440 \mathrm{P})$ ).

\begin{tabular}{|c|c|c|c|c|}
\hline $\begin{array}{l}\text { Samsung UHD Demo } \\
(2 \mathrm{~K}=1440 \mathrm{P})\end{array}$ & Original video & Facebook video & Tumblr video & Twitter video \\
\hline Frame width & 2560 & 1280 & 1280 & 1280 \\
\hline Height & 1440 & 720 & 720 & 720 \\
\hline Data rate & $5667 \mathrm{kbps}$ & $835 \mathrm{kbps}$ & $1280 \mathrm{kbps}$ & $1153 \mathrm{kbps}$ \\
\hline Total bitrate & $5774 \mathrm{kbps}$ & $879 \mathrm{kbps}$ & $1407 \mathrm{kbps}$ & $1284 \mathrm{kbps}$ \\
\hline Frame rate & 30 frames $/ \mathrm{sec}$ & 30 frames $/ \mathrm{sec}$ & 30 frames/sec & 30 frames $/ \mathrm{sec}$ \\
\hline Audio bitrate & $126 \mathrm{kbps}$ & $48 \mathrm{kbps}$ & $126 \mathrm{kbps}$ & $128 \mathrm{kbps}$ \\
\hline Storage size & $20.5 \mathrm{MB}$ & $3.14 \mathrm{MB}$ & $4.99 \mathrm{MB}$ & $4.53 \mathrm{MB}$ \\
\hline Playing length & $29 \mathrm{sec}$ & $29 \mathrm{sec}$ & $29 \mathrm{sec}$ & $29 \mathrm{sec}$ \\
\hline Format (media type) & MP4 (base media) & MP4 (base media) & MP4 (base media) & $\begin{array}{c}\text { MP4 (base } \\
\text { media/version 2) }\end{array}$ \\
\hline
\end{tabular}

TABLE 3: Original versus cloud compressed videos' parameters (Fearless-Daffy-Duck 720 P).

\begin{tabular}{|c|c|c|c|c|}
\hline $\begin{array}{l}\text { Fearless-Daffy-Duck } \\
\text { video properties }\end{array}$ & Original video & Facebook video & Tumblr video & Twitter video \\
\hline Frame width & 1280 & 1280 & 1280 & 1280 \\
\hline Height & 720 & 720 & 720 & 720 \\
\hline Data rate & $1493 \mathrm{kbps}$ & $873 \mathrm{kbps}$ & $1493 \mathrm{kbps}$ & $1361 \mathrm{kbps}$ \\
\hline Total bitrate & $1687 \mathrm{kbps}$ & $920 \mathrm{kbps}$ & $1623 \mathrm{kbps}$ & $1493 \mathrm{kbps}$ \\
\hline Frame rate & 25 frames $/ \mathrm{sec}$ & 25 frames/sec & 25 frames $/ \mathrm{sec}$ & 25 frames $/ \mathrm{sec}$ \\
\hline Audio bitrate & $192 \mathrm{kbps}$ & $48 \mathrm{kbps}$ & $128 \mathrm{kbps}$ & $128 \mathrm{kbps}$ \\
\hline Storage size & $10.9 \mathrm{MB}$ & $5.98 \mathrm{MB}$ & $10.5 \mathrm{MB}$ & $9.65 \mathrm{MB}$ \\
\hline Playing length & $54 \mathrm{sec}$ & $54 \mathrm{sec}$ & $54 \mathrm{sec}$ & $54 \mathrm{sec}$ \\
\hline Format (media type) & $\begin{array}{c}\text { MP4 (Moving Picture } \\
\text { Experts Group version 4) }\end{array}$ & MP4 (base media) & MP4 (base media) & $\begin{array}{c}\text { MP4 (base } \\
\text { media/version 2) }\end{array}$ \\
\hline
\end{tabular}


TABLE 4: Original versus cloud compressed videos' parameters (Motivate yourself $360 \mathrm{P}$ ).

\begin{tabular}{|c|c|c|c|c|}
\hline $\begin{array}{l}\text { "Motivate yourself" } \\
\text { video properties }\end{array}$ & Original video & Facebook video & Tumblr video & Twitter video \\
\hline Frame width & 360 & 360 & 360 & 240 \\
\hline Height & 360 & 360 & 360 & 240 \\
\hline Data rate & $311 \mathrm{kbps}$ & $266 \mathrm{kbps}$ & $311 \mathrm{kbps}$ & $167 \mathrm{kbps}$ \\
\hline Total bitrate & 409 kbps & $289 \mathrm{kbps}$ & $414 \mathrm{kbps}$ & $240 \mathrm{kbps}$ \\
\hline Frame rate & 29.9 frames/sec & 29.97 frames/sec & 29.97 frames/sec & 29.97 frames/sec \\
\hline Audio bitrate & $96 \mathrm{kbps}$ & $20 \mathrm{kbps}$ & $96 \mathrm{kbps}$ & $68.4 \mathrm{kbps}$ \\
\hline Storage size & $2.33 \mathrm{MB}$ & $1.65 \mathrm{MB}$ & $2.35 \mathrm{MB}$ & $1.29 \mathrm{MB}$ \\
\hline Playing length & $47 \mathrm{sec}$ & $47 \mathrm{sec}$ & $47 \mathrm{sec}$ & $47 \mathrm{sec}$ \\
\hline Format (media type) & $\begin{array}{c}\text { MP4 (base } \\
\text { media/version 2) }\end{array}$ & MP4 (base media) & MP4 (base media) & $\begin{array}{c}\text { MP4 (base } \\
\text { media/version 2) }\end{array}$ \\
\hline
\end{tabular}

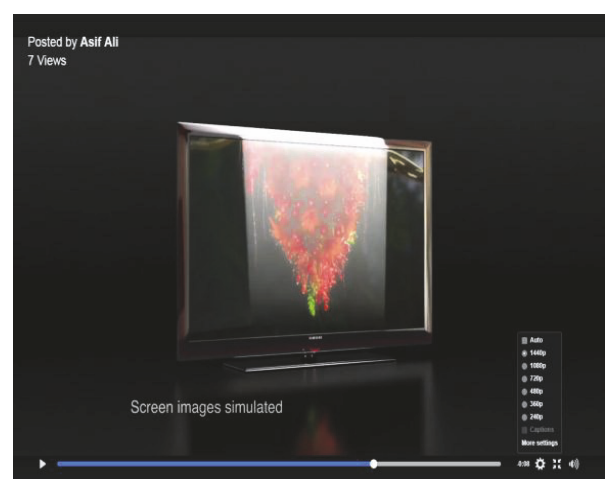

FIGURE 5: Snapshot of Facebook video.

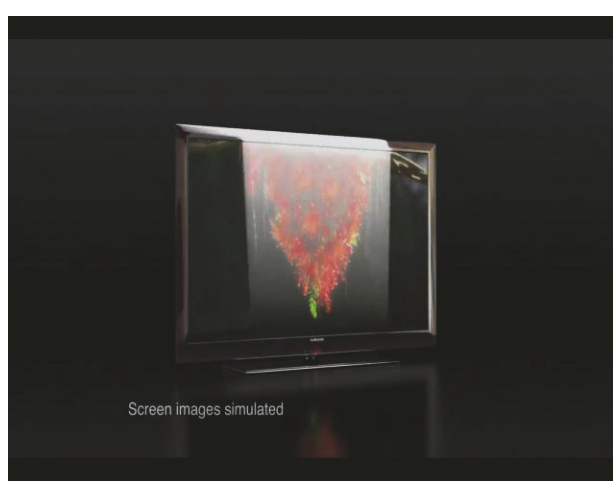

Figure 6: Snapshot of Tumblr video.

which did not impose a high impact on the quality of video as compared to original video as technical information shows in Table 4. Figure 19 illustrates that Facebook and Twitter have less QoE ratings as compared to Tumblr because Tumblr did not compress the original file when it is uploaded on the cloud.

Wildlife $240 \mathrm{P}$ video is the video with lowest quality in all videos used in QoE assessment experiments. Due to the low quality of original video, users assign lowest ratings as compared to other videos. Further social clouds compressed the original video and damaged the quality of video so user

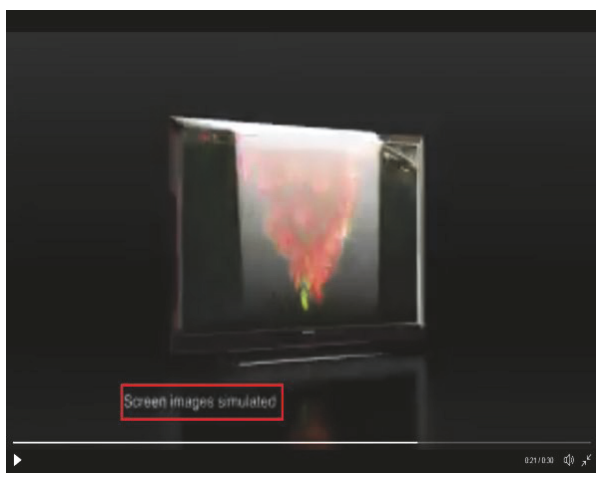

FIgURE 7: Snapshot of Twitter video.

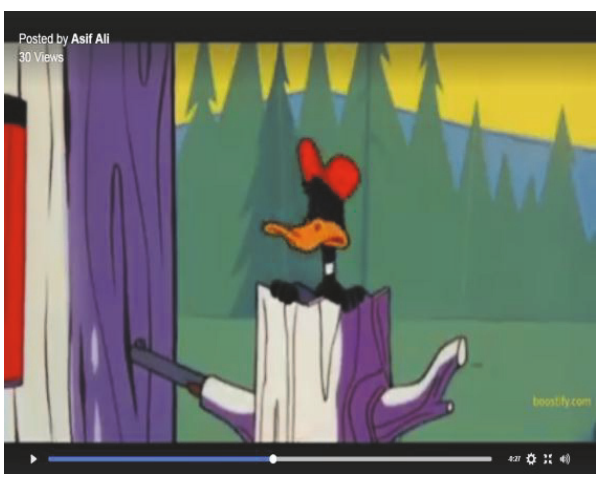

FIGURE 8: Snapshot of Facebook video.

ratings were also low. Tumblr is the only social cloud that did not compress the video but increased bitrate by $1 \%$ and audio bitrate so user assigns marginally high ratings compare to teh other social clouds. User ratings are given in Table 6 and results are also given in Figure 20.

Figure 21 shows the comparison of MOS of all original videos as well as videos compressed by social clouds. Technical information of experiment is a proof that Tumblr compressed less total bitrate and audio bitrate of HD files but did not compress any parameter for low-quality files. Facebook compressed audio bitrate more as compared to the 
TABLE 5: Original versus cloud compressed videos' parameters (Short wildlife video $240 \mathrm{P}$ ).

\begin{tabular}{lcccc}
\hline $\begin{array}{l}\text { Short wildlife video } \\
(240 \mathrm{P})\end{array}$ & Original video & Facebook video & Tumblr video & Twitter video \\
\hline Frame width & 320 & 320 & 320 & 320 \\
Height & 180 & 180 & 180 & 180 \\
Data rate & $269 \mathrm{kbps}$ & $168 \mathrm{kbps}$ & $269 \mathrm{kbps}$ & $157 \mathrm{kbps}$ \\
Total bitrate & $405 \mathrm{kbps}$ & $191 \mathrm{kbps}$ & $407 \mathrm{kbps}$ & $29.97 \mathrm{frames} / \mathrm{sec}$ \\
Frame rate & 29.9 frames/sec & $29.97 \mathrm{frames} / \mathrm{sec}$ & $29.97 \mathrm{frames} / \mathrm{sec}$ & $32.2 \mathrm{kbps}$ \\
Audio bitrate & $128 \mathrm{kbps}$ & $20.1 \mathrm{kbps}$ & $128 \mathrm{kbps}$ & $700 \mathrm{~KB}$ \\
Storage size & $1.45 \mathrm{MB}$ & $717 \mathrm{~KB}$ & $30 \mathrm{sec}$ & $30 \mathrm{sec}$ \\
Playing length & $30 \mathrm{sec}$ & $30 \mathrm{sec}$ & $\mathrm{MP}$ (base \\
Format (media type) & MP4 (base media) & MP4 (base media) & MP4 (base media) & media/version 2) \\
\hline
\end{tabular}

TABLE 6: User MOS.

\begin{tabular}{|c|c|c|c|c|c|c|c|c|c|}
\hline \multicolumn{2}{|c|}{$\begin{array}{l}\text { Samsung UHD Demo } \\
(2 \mathrm{~K}=1440 \mathrm{P})\end{array}$} & \multicolumn{2}{|c|}{$\begin{array}{l}\text { Fearless-Daffy-Duck } \\
(720 \mathrm{P})\end{array}$} & \multicolumn{2}{|c|}{ Motivate yourself (360 P) } & \multicolumn{2}{|c|}{ Short wildlife video (240 P) } & \multicolumn{2}{|c|}{ MOS standard scale } \\
\hline Cloud & MOS & Cloud & MOS & Cloud & MOS & Cloud & MOS & Excellent & 5 \\
\hline $\begin{array}{l}\text { Original } \\
\text { video }\end{array}$ & 4.9 & $\begin{array}{l}\text { Original } \\
\text { video }\end{array}$ & 4.6 & $\begin{array}{l}\text { Original } \\
\text { video }\end{array}$ & 4.1 & $\begin{array}{l}\text { Original } \\
\text { video }\end{array}$ & 3.1 & Good & 4 \\
\hline Facebook & 4.6 & Facebook & 4.1 & Facebook & 3.4 & Facebook & 1.9 & Fair & 3 \\
\hline Twitter & 2.1 & Twitter & 2.8 & Twitter & 2.1 & Twitter & 1.2 & Poor & 2 \\
\hline Tumblr & 4.4 & Tumblr & 4.3 & Tumblr & 3.6 & Tumblr & 2.3 & $\mathrm{Bad}$ & 1 \\
\hline
\end{tabular}

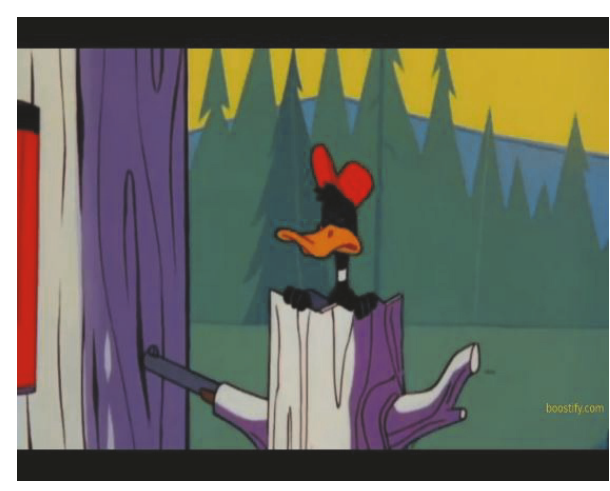

FIGURE 9: Snapshot of Tumblr video.

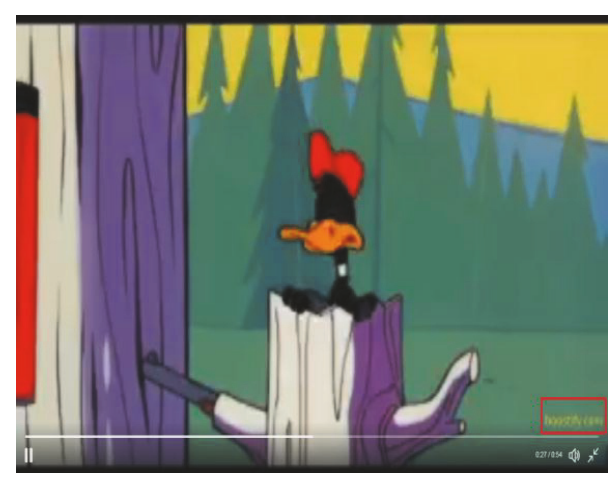

FIgURE 10: Snapshot of Twitter video.

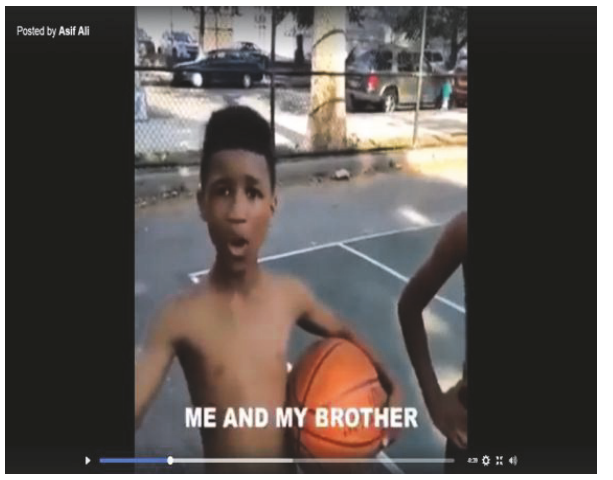

FIgURE 11: Facebook snapshot.

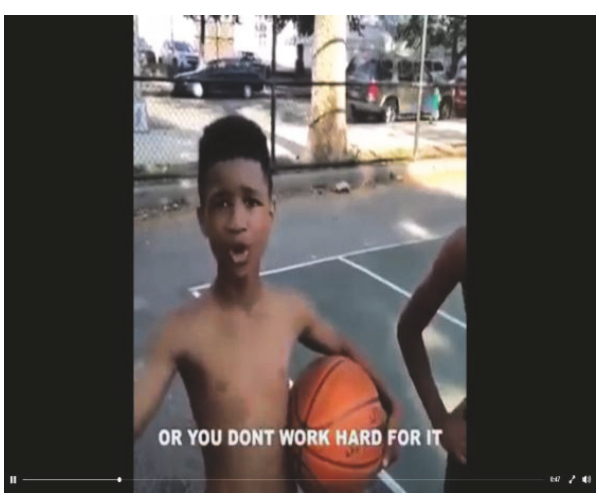

FIGURE 12: Tumblr snapshot. 


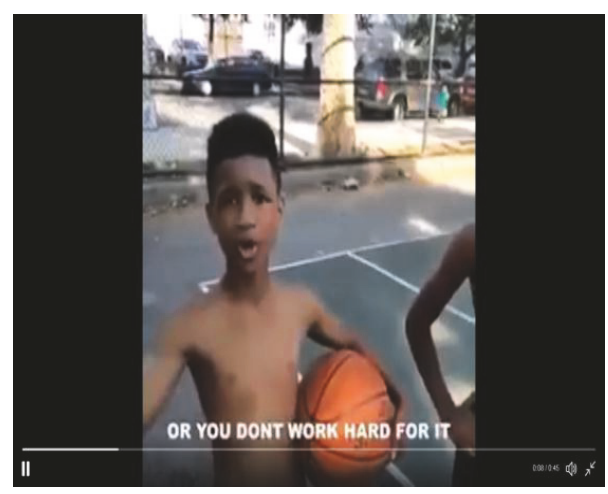

FIgURE 13: Twitter snapshot.

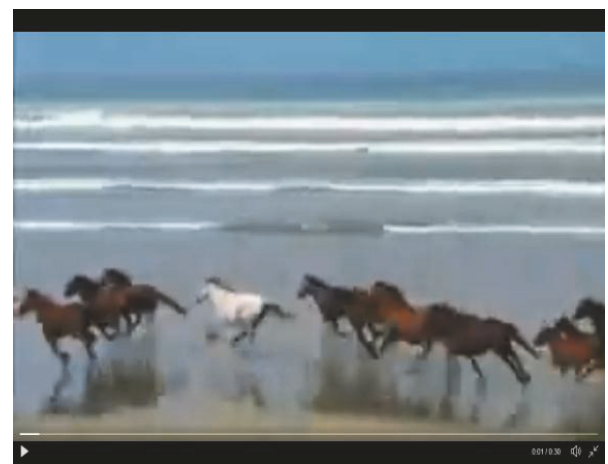

Figure 14: Facebook snapshot.

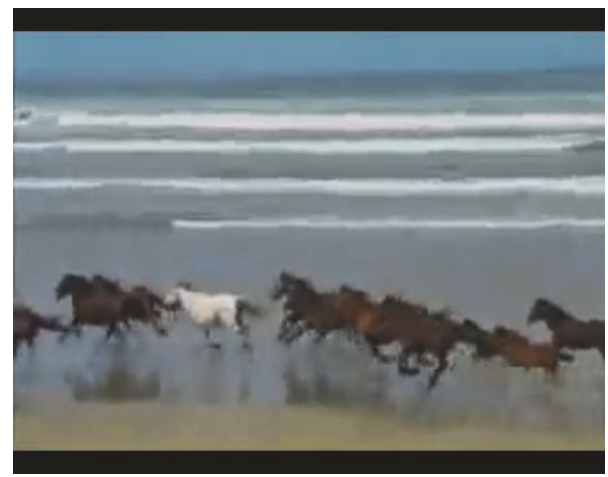

FIGURE 15: Tumblr snapshot.

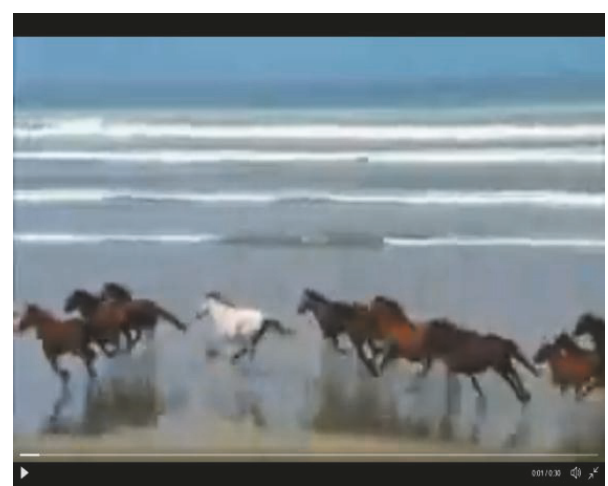

FIgURE 16: Twitter snapshot.

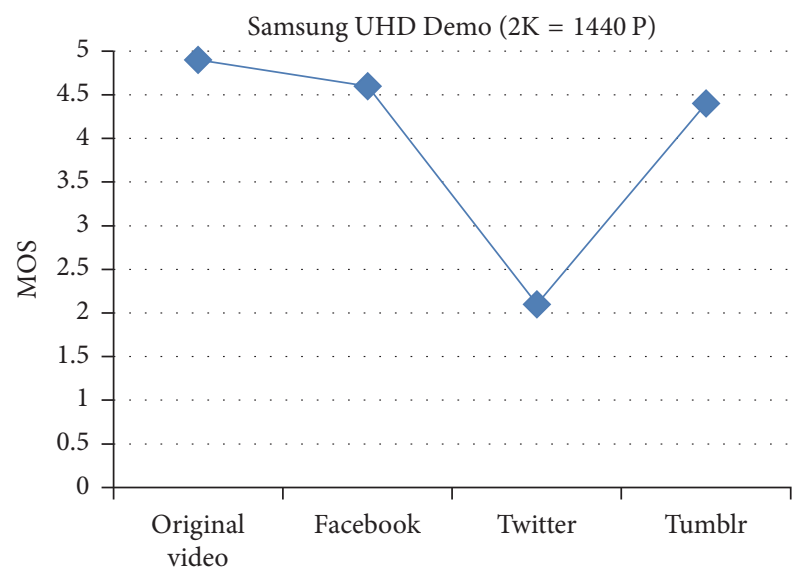

Social clouds

- Samsung UHD Demo $(2 \mathrm{~K}=1440 \mathrm{P}) \mathrm{MOS}$

Figure 17: MOS graph of $1440 \mathrm{P}$ video.

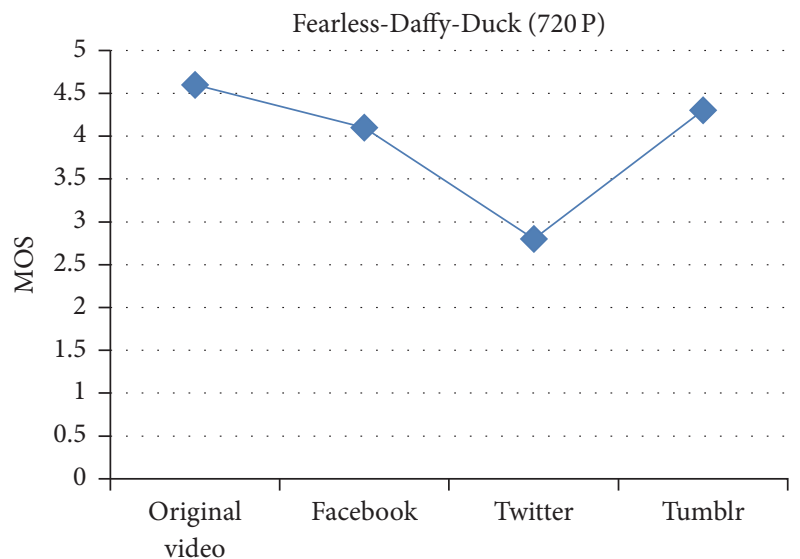

Social clouds

Fearless-Daffy-Duck (720 P) MOS

FIGURE 18: MOS graph of $720 \mathrm{P}$ video.

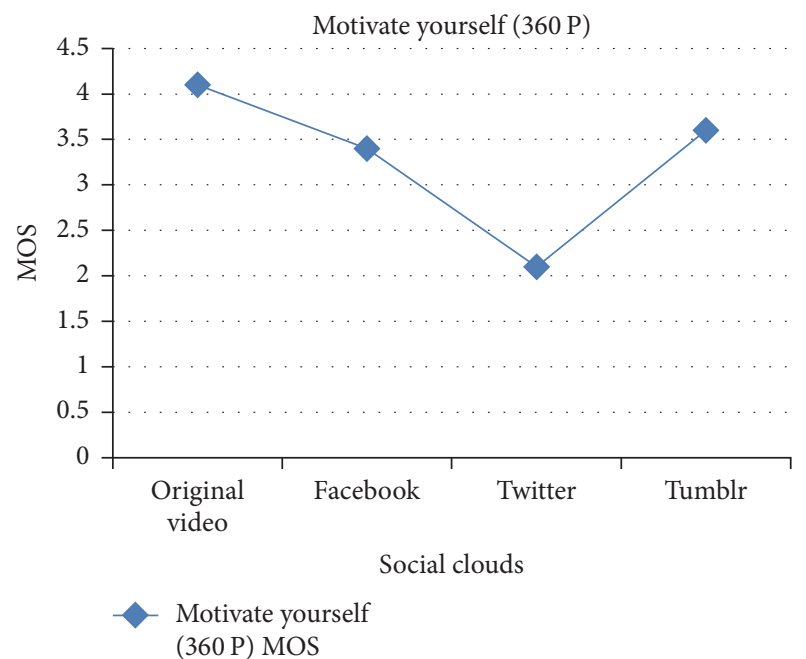

Figure 19: MOS graph of $360 \mathrm{P}$ video. 


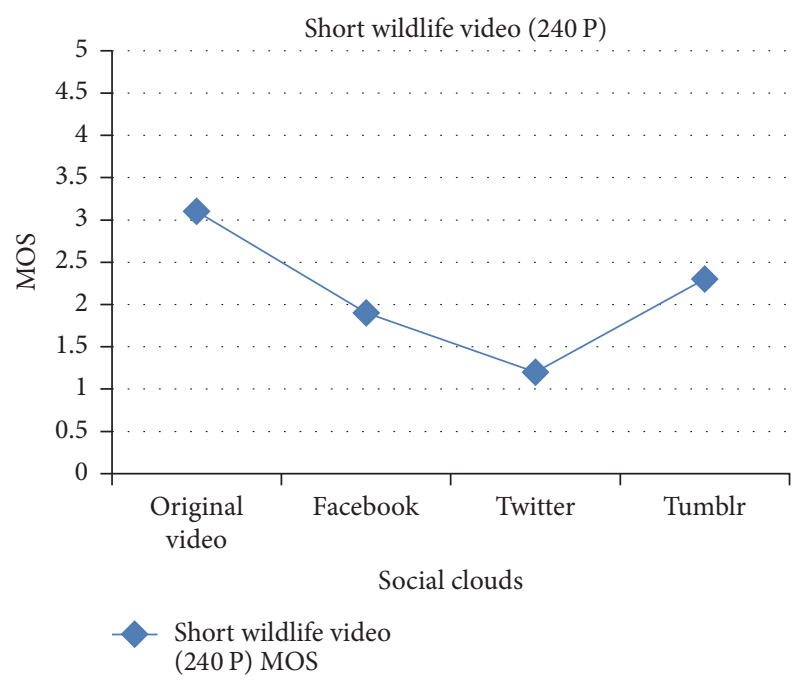

Figure 20: MOS graph of $240 \mathrm{P}$ video.

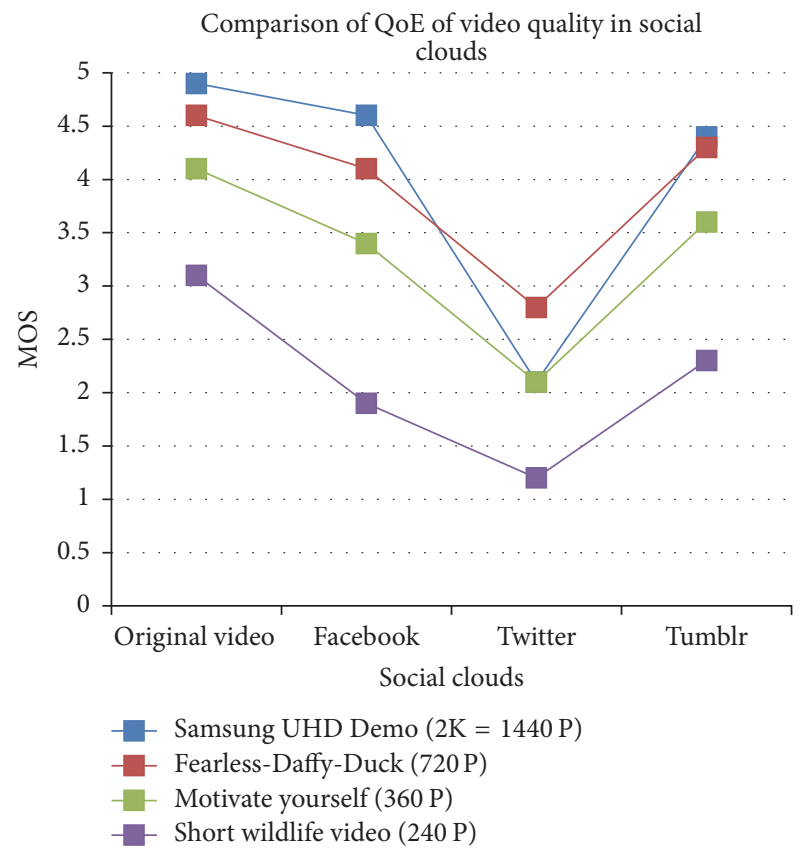

FIGURE 21: MOS comparison of 2K, 720 P, $360 \mathrm{P}$, and $260 \mathrm{P}$ videos.

other social clouds and Twitter compressed data rate and total bitrate of low-quality files to reduce file size. Facebook and Tumblr provide high-quality online video streaming as compared to Twitter for HD video files. Users assign high ratings to a $1440 \mathrm{P}$ video which proves that they like to watch and upload high-quality videos but social clouds compress more $\mathrm{HD}$ videos as compared to low-quality videos: Facebook compressed to $86 \%$ data rate and 84.8 bitrate due to big file size to adjust storage in the cloud data center. The quality of video and size of the file are increased; then compression rate of social clouds increased but due to compression, the quality of video decreased and then user MOS is also decreased.

\section{Conclusion}

In this paper, we conducted several experiments on social cloud video compression and uploaded videos on different popular social clouds to measure user satisfaction level about video quality. The results included in this paper have shown that user satisfaction level is excellent when original videos with high quality were perceived by the user, but ratings were decreased for video quality when videos were posted on Twitter cloud and videos were distorted due to high compression level. Facebook provides good visual quality for $\mathrm{HD}$ videos after compression and plays videos on different quality scales but Tumblr and Twitter do not provide different quality scale playing options for HD-quality videos. This research work provides an assessment of users perception that they suffered from the video quality distortion due to compression of social clouds and final visual quality is decreased below fair for Twitter, which is given in scale of MOS.

\section{Conflicts of Interest}

The authors declare that they have no conflicts of interest.

\section{Acknowledgments}

This work is supported by the National Key R\&D Program of China under Grant no. 2017YB0801801 and the National Natural Science Foundation of China (NSFC) under Grant no. 61472108 .

\section{References}

[1] I. Amerini, R. Caldelli, A. D. Mastio, A. D. Fuccia, C. Molinari, and A. P. Rizzo, "Dealing with video source identification in social networks," Signal Processing: Image Communication, vol. 57, pp. 1-7, 2017.

[2] J. Chakareski, "Adaptive multiview video streaming: challenges and opportunities," IEEE Communications Magazine, vol. 51, no. 5, pp. 94-100, 2013.

[3] W. Zhang, Y. Zhang, and T.-H. Kim, "Detecting bad information in mobile wireless networks based on the wireless application protocol," Computing, vol. 96, no. 9, pp. 855-874, 2014.

[4] W. Zhang, G. Lu, H. He, Q. Zhang, and C. Yu, "Exploring large-scale small file storage for search engines," The Journal of Supercomputing, vol. 72, no. 8, pp. 2911-2923, 2016.

[5] J.-S. Lee and T. Ebrahimi, "Perceptual video compression: A survey," IEEE Journal of Selected Topics in Signal Processing, vol. 6, no. 6, pp. 684-697, 2012.

[6] H. Yuan, C. Guo, J. Liu, X. Wang, and S. Kwong, "Motionhomogeneous-based fast transcoding method from H.264/AVC to HEVC," IEEE Transactions on Multimedia, vol. 19, no. 7, pp. 1416-1430, 2017.

[7] T. Hoßfeld, R. Schatz, E. Biersack, and L. Plissonneau, "Internet video delivery in youtube: from traffic measurements to quality of experience," in Data Traffic Monitoring and Analysis, vol. 7754, pp. 264-301, 2013.

[8] W. He, H. Wu, G. Yan, V. Akula, and J. Shen, "A novel social media competitive analytics framework with sentiment 
benchmarks," Information and Management, vol. 52, no. 7, pp. 801-812, 2015.

[9] A. A. Laghari, H. He, S. Zardari, and M. Shafiq, "Systematic Analysis of Quality of Experience (QoE) Frameworks for Multimedia Services," IJCSNS, vol. 17, no. 5, p. 121, 2017.

[10] Z. Cheng, L. Ding, W. Huang, F. Yang, and L. Qian, "Subjective QoE based HEVC encoder adaptation scheme for multi-user video streaming," in Proceedings of the 2016 IEEE International Symposium on Broadband Multimedia Systems and Broadcasting, BMSB 2016, pp. 1-6, June 2016.

[11] A. A. Laghari, M. I. Channa, K. R. Laghari, M. Aman, and M. Memon, "EQOM: enhanced quality of experience (QoE) framework for multimedia services," UACEE International Journal of Computer Science and Its Applications, vol. 3, no. 1, pp. 85-89, 2013.

[12] A. A. Laghari, K. R. Laghari, M. I. Channa, and T. H. Falk, "QON: quality of experience (QoE) framework for network services," in Proceedings of the 4th International Conference on Software Technology and Engineering, (ICSTE'12), 2012.

[13] A. A. Laghari, H. He, M. Shafiq, and A. Khan, "Assessing effect of cloud distance on end user's quality of experience (QoE)," in Proceedings of the 2016 2nd IEEE International Conference on Computer and Communications (ICCC), pp. 500-505, Chengdu, China, October 2016.

[14] B. Cheng, "MediaPaaS: A cloud-based media processing platform for elastic live broadcasting," in Proceedings of the 7th IEEE International Conference on Cloud Computing, CLOUD 2014, pp. 713-720, July 2014.

[15] Q. Wang, K. Xu, R. Izard et al., "GENI cinema: An SDN-assisted scalable live video streaming service," in Proceedings of the 22nd IEEE International Conference on Network Protocols, ICNP 2014, pp. 529-532, October 2014.

[16] I.T.U. Assembly, Radiocommunication. Methodology for the subjective assessment of the quality of television pictures. International Telecommunication Union, 2003.

[17] ITU-T Recommendation P, "Subjective video quality assessment methods for multimedia applications," pp. 34-35, 1999.

[18] https://www.youtube.com/watch?v=R3GfuzLMPkA.

[19] https://www.youtube.com/watch.

[20] https://www.youtube.com/watch?v=bwgmiJ0Yl-M.

[21] https://www.youtube.com/watch?v=5DP5I8Gd6wY.

[22] https://www.videolan.org/index.html.

[23] https://www.videohelp.com/software/MediaInfo.

[24] (poor quality video by twiter), https://twittercommunity.com/ t/poor-quality-video-on-twitter-why/68827. 


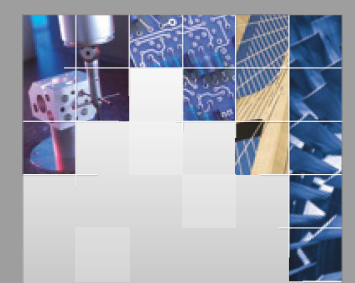

\section{Enfincering}
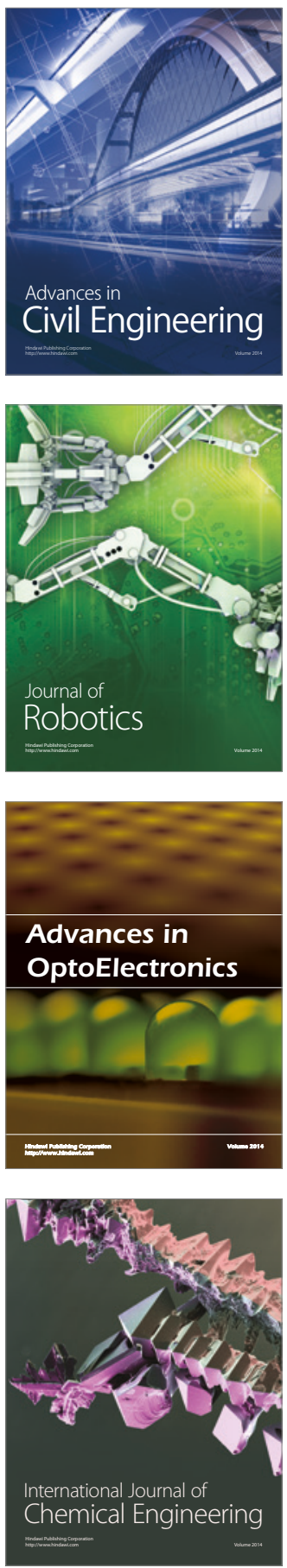

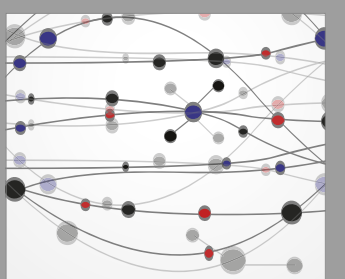

The Scientific World Journal

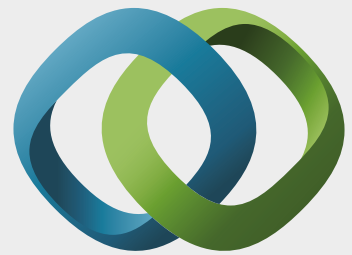

\section{Hindawi}

Submit your manuscripts at

https://www.hindawi.com
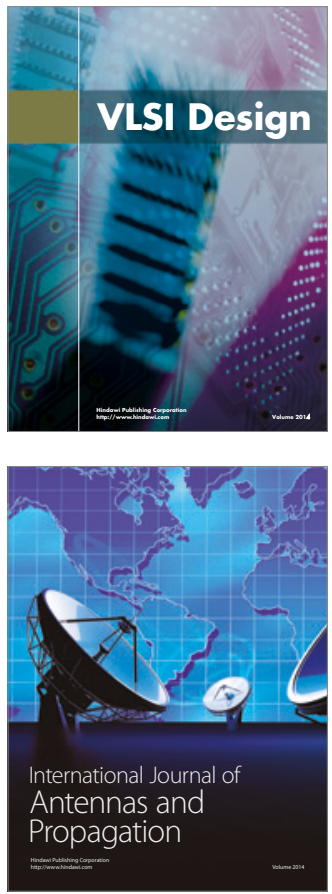

\section{Rotating}

Machinery
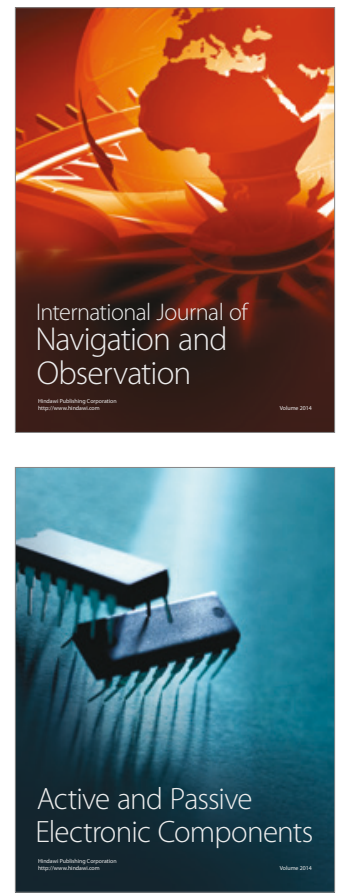
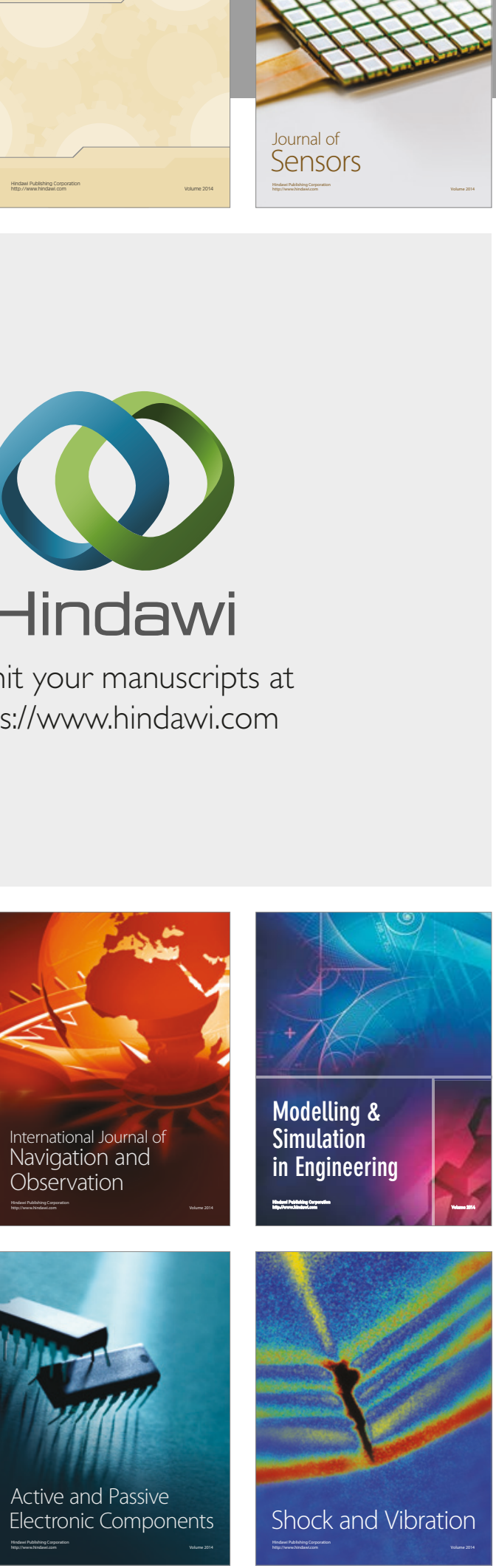
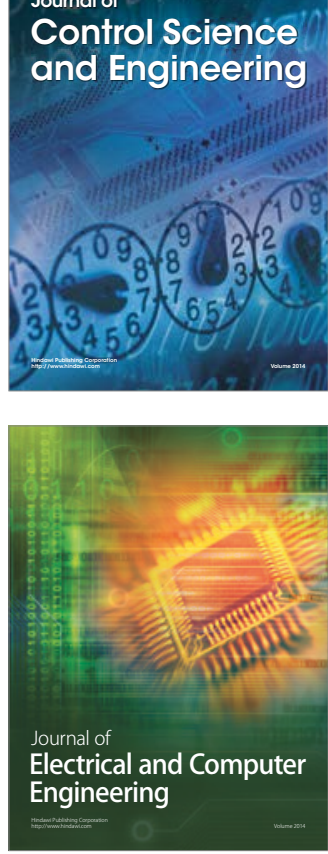

Distributed

Journal of

Control Science

and Engineering
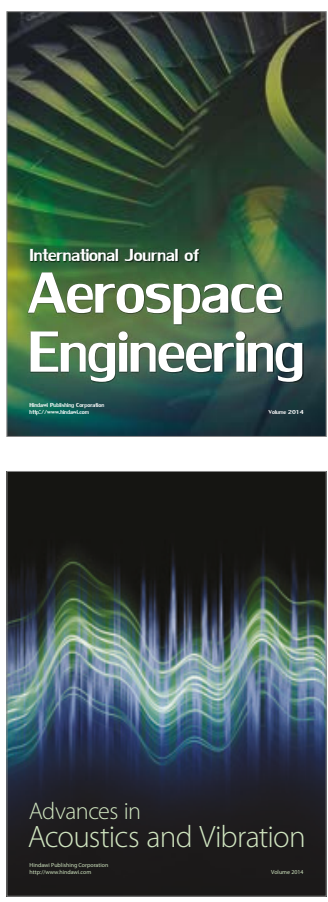

Sensor Networks 